C2020, Elsevier. Licensed under the Creative Commons Attribution-NonCommercial-

NoDerivatives 4.0 International http://creativecommons.org/about/downloads

(c)

Full version of can be found at Taylor, Francesca, Drennan, Vari M, Halter, Mary and Calestani, Melania (2020) Integration and retention of American physician assistants/associates working in English hospitals : a qualitative study. Health Policy, 124(5), pp. 525-530.

https://doi.org/10.1016/j.healthpol.2020.03.001 


\section{Integration and retention of American physician assistants/associates working in English hospitals: a qualitative study}

Francesca Taylor ${ }^{\mathrm{a} *}$

${ }^{a}$ Centre for Health \& Social Care Research, Joint Faculty of Kingston University and St George's University of London, St George's University of London, Cranmer Terrace, London SW17 ORE, UK francesca.taylor@sgul.kingston.ac.uk +44(0)20 $87252800 /+44(0) 7775531674$

Vari M Drennan ${ }^{\mathrm{a}}$

${ }^{a}$ Centre for Health \& Social Care Research, Joint Faculty of Kingston University and St George's University of London, St George's University of London, Cranmer Terrace, London SW17 ORE, UK

v.drennan@sgul.kingston.ac.uk

Mary Halter ${ }^{\mathrm{a}}$

${ }^{a}$ Centre for Health \& Social Care Research, Joint Faculty of Kingston University and St George's University of London, St George's University of London, Cranmer Terrace, London SW17 ORE, UK

maryhalter@sgul.kingston.ac.uk

Melania Calestani ${ }^{\mathrm{b}}$

${ }^{b}$ School of Allied Health, Midwifery and Social Care, Joint Faculty of Kingston University and St George's University of London, St George's University of London, Cranmer Terrace, London SW17 ORE, UK m.calestani@sgul.kingston.ac.uk

*Corresponding author

\section{Conflict of interest}

The authors of this study declare that they have no competing interests.

\section{Acknowledgements}

This work was supported by a National Health Service (NHS) innovation and workforce development fund for evaluation of the National Physician Associates Expansion Programme administered by Hillingdon Hospitals NHS Foundation Trust. The views expressed in this paper are those of the authors and not those of the funders or the NHS. The authors would like to thank the PA participants whose involvement made the study possible, the National Physician Associates Expansion Programme and patient and public members of the Patient Research Expert Group who were involved in the study design. 


\title{
Integration and retention of American physician assistants/associates working in English hospitals: a qualitative study
}

\begin{abstract}
Background: Health workforce planners in many high-income countries are considering policy strategies to retain home and overseas-trained health professionals. There is a lack of evidence on how hospitals can successfully integrate and retain skilled overseas professionals in relevant work roles. This study aimed to explore the integration and retention experiences of skilled American physician assistants/associates working in English hospitals.
\end{abstract}

Methods: A qualitative study using semi-structured telephone interviews was undertaken in spring 2017 and spring 2018. Data were coded and analysed using thematic analysis. The study was framed within a theoretical model of role development.

Results: Nineteen physician assistants/associates participated in interviews at timepoint one, and seventeen at timepoint two, across seven English hospitals. Four themes were identified in the integration and retention processes experienced by participants: motivations and expectations, seeking role identity, acceptance and integration, and establishing a niche role. Supervising doctors appeared instrumental in creating opportunities through training and system adjustment that enabled development of niche roles; offering an effective match between participant skills and interests, and medical/surgical team or organisational needs. Whether or not they had a niche role influenced the decision of participants to remain or leave.

Conclusion: Integration approaches that maximise the value of the skilled health professional to the medical/surgical team and support retention, including development of optimum roles, require time and resources. 


\section{Integration and retention of American physician assistants/associates working in English hospitals: a qualitative study}

\section{Introduction}

Health workforce shortages, current and future, are a major policy issue globally [1-3]. The World Health Organisation (WHO) advocates policy action at multiple points in a health labour market model of supply, demand, and deployment [1,2]. One such policy initiative particularly addressing medical staff shortages and maldistribution, is the adoption of mid-level provider or advanced clinical practitioner-type roles [1]. Physician assistants, known as physician associates (PAs) in the United Kingdom (UK), are one such role. PAs are trained at postgraduate level to work in any clinical speciality within medical and surgical teams. They undertake medical histories, physical examinations, diagnoses and treatment within their scope of practice, under doctor supervision and in line with local legislation [4,5]. PAs in the UK cannot prescribe medicines or order ionising radiation, unlike in the US [4]. However, following a public consultation in 2018, the UK Government announced arrangements to regulate PAs [6].

PAs have a fifty-year history in the United States (US) and are developing in other countries worldwide [4,7], but are still a novelty in the UK. UK-trained PAs first entered the English National Health Service (NHS) workforce in very small numbers from 2009 onwards [8]. Policy announcements in 2014 [9], and reconfirmed in 2019 [10], provided public funding to support training and an increase in PA graduates from around 200 in 2015 to over 2,800 by the end of 2020, in response to ongoing shortages of doctors. Nevertheless, prior to this large number of UK-trained PAs entering the workforce, and with demand for PAs increasing, English NHS hospitals looked for trained PAs from outside the UK [11].

The recruitment of overseas health professionals has been a widely deployed policy to address health workforce gaps [12]. Many high-income countries rely heavily on overseas professionals to staff their health systems, recruited from across low to high-income countries. Over the past decade Australia, New Zealand, and the UK for example, have invariably had more than $20 \%$ overseas doctors and $13 \%$ overseas nurses in their workforce [13]. To reduce over-dependence on overseas recruits, the retention of both home and overseas health 
professionals is an increasingly important policy concern, alongside interest in more effective strategies to integrate recruits $[3,14-16]$.

Existing literature is strong on examining the motivational factors influencing the movement of skilled health professionals between high-income countries, with a complex range of interlocking personal and professional push-pull factors identified at the micro, meso and macro level [17-23]. There is also evidence on the personal and professional issues affecting their integration and retention in hospitals. Facilitators include improved working conditions, better training and career opportunities, increased patient contact, and attractive lifestyle [2022]. Barriers encompass diminished status, professional isolation, and restricted skill-sharing and career development $[19,20,24]$. However, there is a lack of evidence on organisationrelated influences on the integration and retention of these skilled overseas employees, in particular, how hospitals can successfully integrate them into relevant and attractive work roles.

Our study seeks to address this evidence gap by reporting on the experiences of skilled health professionals, in this case PAs, recruited from one high-income country where the role was well embedded, the US, to another high-income country, the UK, where the role was in its infancy. Specifically, it reports the experiences of integration and retention in work roles of experienced American PAs working in English NHS hospitals. The recruitment and deployment of these skilled overseas PAs was administered by an innovative workforce programme, conceived to offer English NHS hospitals an understanding of what experienced PAs could offer their services over a two-year period, contemporaneous with the expansion in PA training programmes [11].

To understand better the processes of integration and retention of the American PAs into work roles, we used Toffler's role development theory [25] as a framework for the study. Traditional role development theory stresses that new employees actively influence their work environment in the process of defining their roles [25,26]. Toffler [25] described role development as a gradual and dynamic process during which new employees reach consensus with other organisational members about their specific role within the requirements of both job and organisation. The aims of the study were to explore the experiences of skilled American PAs recruited to English NHS hospitals in relation to their (1) integration into medical and surgical hospital team roles, and (2) retention by their host hospital. Specifically, how does role development influence the integration and retention of skilled overseas PAs? 


\section{Methods}

\subsection{Study design}

A qualitative design was used in the interpretative tradition [27] to enable insights into the experiences of the PAs [28]. Semi-structured interviews were undertaken over the telephone at two time-points: at eight months, and twenty months, into the two-year workforce programme. The interviews consisted of a series of open-ended questions with supplementary prompts to allow key issues to be explored without being prescriptive about content and direction [29]. The interview guide used at timepoint one aimed to explore the PAs' migration expectations; initial work experiences; and any facilitators and barriers to their integration within medical/surgical teams. At timepoint two, the interview guide aimed to elicit the PAs' work experiences over time; any changes in their role and integration within medical/surgical teams, and related facilitators/barriers; perceived influences on role development; and views about future employment. Interviews were audio-recorded, transcribed verbatim, and the transcripts checked against recordings.

\subsection{Data collection}

Inclusion criteria specified American PAs recruited to the workforce programme who had been employed in one of the English hospitals involved in the programme. All the PAs who met the inclusion criteria were sent an initial invitation enquiring about participation in the study - by the programme leads at timepoint one, and by the study principal investigator (VMD) at timepoint two. The contact details of PAs expressing interest in participation were passed to study researchers who then sent the PAs a participant information sheet and a consent form.

Twenty-one PAs (76\% of eligible PAs) participated in the study. Nineteen PAs consented to be interviewed at timepoint one, and 17 PAs at timepoint two. Fifteen PAs interviewed at timepoint one were interviewed at timepoint two, and two additional PAs at time point two only. Interviews took place in spring 2017 and spring 2018. Interviews lasted 19 to 50 minutes (median 34) at timepoint one, and 44 to 69 minutes (median 57) at timepoint two. Access and consent processes complied with ethical principles [30]. 


\subsection{Data analysis}

Data sets collected at the two study timepoints were initially analysed separately using thematic analysis (MC, FT) [29]. The analysis was informed by the study topic guide and the theoretical framework of the study [25]. Data were broken down using line-by-line coding and the codes clustered manually to identify preliminary categories based on issues and themes. These were scrutinised and discussed with the principal investigator (VMD) who read transcripts from a sub-sample of interviews from each data set. Two separate frameworks were developed from the analyses, together with code-books, and used to structure verbatim responses onto spreadsheets. Codes and themes included in each of the frameworks were refined and elaborated collectively with data collected from further interviews, some combined and others condensed or removed. NVIVO V.11 software (QRS International) supported coding. A further stage of synthesis was undertaken (FT, VMD) to describe and interpret findings, looking for triangulation of themes, patterns, and plausible explanations across the two data sets, before confirmation of themes.

\section{Results}

All study participants had previously worked as PAs in the US for between five and 23 years. They were employed across seven hospital study sites including four urban teaching hospitals, two urban speciality hospitals, and one district general hospital. The participants also worked across different specialities (Table 1).

Table 1 Study participants by speciality

\begin{tabular}{lcc} 
Speciality & $\begin{array}{c}\text { Number of study participants } \\
\text { at time point one }\end{array}$ & $\begin{array}{c}\text { Number of study participants } \\
\text { at time point two }\end{array}$ \\
\hline Acute internal medicine & 5 & 3 \\
Other adult medical specialities & 8 & 8 \\
Adult surgical & 4 & 4 \\
Emergency medicine & 1 & 1 \\
Paediatric & 1 & 1 \\
\hline
\end{tabular}

Sixteen participants had experience of working in the specialities in which they were employed in English hospitals, and five participants did not. In total there were 19 female and two male participants. All 19 participants at timepoint one were working in the UK, but two participants 
had already decided to leave the workforce programme and were returning to the US. Fourteen of the 17 participants at timepoint two were working in the UK, three participants had left their posts prior to completion of the workforce programme and returned to the US, and ten participants actively planned to extend their contract beyond the two-year programme.

The data analysis process resulted in identification of four themes, each with dominant timepoints when theme data were generated: 'Motivations and expectations' (timepoint one), 'Seeking role identity' (timepoints one and two), 'Acceptance and integration' (timepoints one and two), and 'Establishing a niche role' (timepoint two).

\subsection{Motivations and expectations}

All participants reported multiple migration motivations. The desire to work in and experience another country was the most frequently mentioned. For some participants this motivation was linked to experiencing a different health system. Several participants reported that an important stimulus was the opportunity to promote the PA profession. The proximity of England to mainland Europe was an attraction for participants whose motivations included travelling. A few participants mentioned seeking change and new opportunities in their working lives more generally.

"It sounded like an adventurous opportunity...something that I thought that would benefit my career and also allow me to help promote and encourage PAs as a new profession in another place.” (Participant 2)

Participants described their expectations in terms of benefits to them as individuals and benefits to the host hospital. Some participants spoke about the attractiveness of the workforce programme in relation to career development, envisaging opportunities for further professional training. Two participants who had held senior positions in the US reported expectations of leadership roles. Other participants talked about perceiving themselves as pioneers for the PA profession. They anticipated being an advocate, promoting the values of the profession to a hospital and staff naive to the concept. For some participants, teaching student PAs was expected to be an integral part of role promotion. 
"To lead by example, show them what we can do so that they're more familiar with this concept ...To do a lot of teaching, not just clinical work but also promoting what I do and what my role is." (Participant 13)

One participant mentioned not expecting a "carved out" role since PAs were unknown to their hospital, with the onus on them personally to "forge" a role over time. Nonetheless, all participants expected the workforce programme and hospitals to support and encourage them in establishing their role.

\subsection{Seeking role identity}

The early months in their posts were described as challenging by most participants, particularly in terms of ascertaining their role. Lack of role clarity and associated problems permeated participants' accounts. Some participants talked about being used to fill staffing gaps in medical rotas, rather than having a specific role employing their expertise to best advantage for a medical/surgical team. Where supervising doctors were able to provide a role description, more positive experiences were reported. Opportunities to review the role with a supervising doctor were commented on favourably by a few participants.

"The main guy that I've been working with [...] had a rough plan, a rough outline of what my job role would be, which was really great because it at least gave me an idea of what they were expecting of me, and then I was able to take that and really help define the role." (Participant 14)

Many participants also mentioned being aware of potential role boundary tensions within medical/surgical teams, especially among junior doctors worried about restricted learning opportunities. However, after a period of establishing relationships and sorting out misunderstandings around role content, many of these tensions were reported to have dissipated. One participant reported how both practical demonstration of their role and discussions with junior doctors in their team were needed to address misconceptions. The importance of a supportive supervisor for facilitating the PA's integration into their team was also mentioned by several participants.

"Sometimes it's a little sensitive making sure that I'm not stepping on the junior doctors' toes ...What I think is good is that my consultant doctor is aware of that, so kind of outlined my job 
plans so that my work wouldn't directly interfere with the junior doctors' learning." (Participant 11)

All participants impressed how not having the legal authority in England that they had in the US to prescribe medicines or order ionising radiation, had negative consequences for their role identity, with restrictions on the work they were given, and skills they were able to use.

"The thought was that I might start seeing some more urgent referrals that come through the GP...the problem is I just need to have a consultant or a registrar available if I need to request scans or prescribe anything. So that's the one downfall." (Participant 19)

\subsection{Acceptance and integration}

Many participants described positive changes over time in how their supervising doctor and medical/surgical team members perceived and accepted the PA role. In particular, participants reported that recognition their role offered continuity to staff and to patients resulted in them being used as a skills and knowledge resource. One participant talked about junior doctors at the start of a new rotation asking their clinical advice about patients on the ward. Another participant reported how they were relied on by their supervising doctor to follow-up on patient procedures to prevent "things getting lost in the cracks." Some participants talked about the satisfaction derived from becoming more integrated into their teams.

"I think as my role has become more ingrained in the department and people come to me first for a lot of things or, you know, use me as a resource, that's quite rewarding." (Participant 8)

Acceptance within medical/surgical teams encouraged several participants to seek opportunities to use more of their skills and experience; thereby expanding their role. Some participants described initiating quality improvement projects, adjusting their expertise to match identified team needs. For example, developing a database on the clinical status of inpatients with a particular condition, in order to speed discharge. However, a few participants described working all the time with different doctors. They reported it was therefore difficult to achieve a level of trust in the working relationship where they felt able to utilise their experience.

Several participants mentioned promoting the PA role more actively over time. For some participants this work involved engaging in a local University PA programme, mentoring PA 
students, or supporting clinical placements. Ambassadorial activity was also mentioned, including giving presentations about the PA role to medical consultants and other clinical staff. Two participants said they had been asked by hospital senior management to provide advice on a business case for new PA posts.

More negatively, a few participants expressed frustration at not having had the opportunity to engage in any promotional activity for the PA profession. They talked about feeling disappointed in their host hospital since they had anticipated this type of work to be a key component of their role.

"I was expecting to have more interaction with PA students, whether it was going to be in terms of being a preceptor for them, or maybe visiting their school and either just formally or informally talking about the profession." (Participant 10)

Additionally, some participants mentioned feeling "let down" by the workforce programme during its second year. A few participants expressed resentment that expected support for career development had not been forthcoming, especially provision of teaching opportunities and continuing professional development events.

\subsection{Establishing a niche role}

Being able to develop a specific role or specialist contribution was frequently mentioned by participants as a significant motivator to extending their contract. Several participants described a niche role of which they were proud for having taken on responsibility within their medical/surgical team. Examples included providing a pre-operative clinic for cardiac surgeons, and responsibility for an outpatient orthopaedic clinic to assist increased patient flow. Participants reported feeling an integral and valued member of their medical/surgical team as a consequence.

"I feel like I'm making a difference...I feel like a valued member of my team and I think that the role really fits what I do...it's hard to leave something when you're happy." Participant 14

The importance of a supportive supervisor was mentioned by several participants as being a key enabler in establishing a niche role. They described constructive and encouraging interactions with their supervisor. A process of discussing role opportunities alongside the PA's skills and interests was felt to contribute to a better, shared understanding of how the role might 
develop, ensuring skills were tailored to the specific needs of the medical/service team or hospital.

Some participants reported the development and use of higher level clinical/surgical skills linked to supervisor-led training. Examples of these skills included administering lidocaine infusions to patients with oral lesions requiring biopsy, and assisting with percutaneous endoscopic gastronomy (PEG) placements.

"One of my consultants he's trained me up to assist with PEG tube placements and he has a usual Monday list where before he would sort of have to rely on making sure that that was covered with a registrar, nurse and doctor, whereas now I'm always there." (Participant 1)

While early leavers from their posts returned to the US for a range of different reasons, reported influential elements included not finding satisfying work that met their expectations, not being able to create a recognised niche role within their medical/surgical team, and limited supervisor support. One participant who had decided not to extend their contract mentioned having worked for several different consultants with no support to develop the PA mentoring role they had expected.

"I don't think that in most areas that I've really developed as much as I would have liked to, you know, my role, because I'm just put into seven to eight different clinical practices at some point each week." (Participant 7)

\section{Discussion}

This qualitative study found that organisational uncertainties about the PA role impacted on the early integration experiences of skilled American PAs in English hospitals. These uncertainties concerned how the PA role was to be defined and delivered as well as how it might affect the roles of other medical/surgical team members. Contributory factors to the uncertainties included staff being naive about the PA role, poor awareness and understanding of the skills and competencies of the PAs, and confusion over how to manage their lack of authority in England to prescribe and order ionising radiation. These experiences accord with Toffler's perceptions of role ambiguity; reflecting lack of information communicated and organisational clarity about the expected role [25]. 
In the absence of role clarity, study participants reported how they had attempted both to reduce uncertainties associated with their role, and to demonstrate how the role might function. Participants spoke about being conscious of not "stepping on the toes" of other medical/surgical team members, and working hard to impress each doctor with whom they worked through demonstration of their skills and competencies. Acclimatisation behaviour has been documented in other studies of skilled overseas health professionals [23,24]. This study provides new insights into how participants' roles changed and developed over time and also the two key influencing factors to integration and retention. These were the personal expectations and interests that participants brought to their employment, and participants' adaptation and development of their skills (as well as their expectations) to meet the needs of their medical/surgical teams and hospitals. This reflects Toffler's theory that role changes are the result of actual work activities, and discrepancies between pre-job expectations and job realities [25].

Our findings showed that supervising doctors exerted considerable positive or negative influence over participants' role development. A constructive, collaborative working relationship between supervising doctor and PA was very important in enabling apposite role changes. There was a consultative process over time which led to a shared understanding of the most appropriate scope for a particular PA's role. Supervisors were also instrumental in the creation of opportunities for PAs through training and system adjustment that enabled development of niche roles; offering an effective match between their skills and interests, and medical/surgical team or hospital needs. Evidence suggests that new niche nursing roles, such as a Dermatology Nurse Specialist, also develop organically over time [31]. For many participants in this study, the development or not of a niche role appeared to influence significantly their decision whether or not to extend their employment contract. This is in line with existing evidence that shows finding a niche role positively influences the integration and retention of experienced hospital nurses [32], registered nurses returning to practice [33], and skilled overseas-trained midwives working in different health organisations [34].

The workforce programme that our study participants were part of had been expected by participants to support their role development. The perceived absence of this support contributed to the decision of some participants to leave the programme early. Resourced only as a front loaded, standalone programme may have influenced this situation. Previous UK-led 
recruitment programmes for overseas health professionals have also been found to be under resourced [35].

A major strength of this study is that it was undertaken at two different timepoints. Existing studies on the retention and integration of skilled overseas health professionals have tended to focus on understanding experiences at a specific time. This study allowed an exploration of the longitudinal experiences of participants. Theoretical framing for the study contributed causal links and explanations to help in understanding the process of role development, and its influence on participants' integration and retention experiences.

The main study limitation was that the volunteer participants were self-selecting rather than purposively recruited. However, just over three-quarters of eligible PAs participated, representing diversity in the hospitals and medical/surgical specialities they worked. We chose to use telephone methods to overcome logistical problems of access. While some studies suggest that telephone interviews deliver lower quality data due to missed reporting, others argue the same quality of data can be collected as face-to-face interviews [36]. As a qualitative study the findings cannot be easily generalised, although they offer insights and theoretical framing for future testing. There is value in future research considering the influence of role development on the integration and retention experiences of skilled overseas health professionals working in other new hospital roles as well as in more established roles.

\section{Conclusions}

Health workforce planners in many high-income countries are considering policy strategies to integrate and retain overseas as well as home health professionals. This is recognised as a more effective and sustainable policy option to address current and predicted future workforce shortages than continued over-reliance on overseas recruitment. This paper offers insights for those shaping and implementing these policies. Although the particular cadre of overseas health professionals were recruited to an unusual work environment, in that the role was novel to the English NHS, many health professional roles are enacted differently in different health systems. Skilled health professionals motivated to move between high-income countries are valuable assets in terms of each professional's knowledge, skills and experience. Successful integration and retention of these professionals requires attention to the supporting work structures and environment at the medical/surgical team and broader organisation level. Integration approaches that maximise the value of the skilled professional to the 
medical/surgical team and enables their retention - including development of optimum work roles - take time and resources.

\section{Ethical approval}

The study was approved by the host University (FREC 2017-01-008) and a UK NHS Research Ethics Committee (18/N1/0026).

\section{Data sharing}

De-identified datasets analysed in the current study are available from the corresponding author on reasonable request.

\section{References}

[1] World Health Organization. Global strategy on human resources for health: Workforce 2030. Geneva, Switzerland: WHO Press; 2016. Available at: https://www.who.int/hrh/resources/pub_globstrathrh-2030/en/ [accessed 06.09.19]

[2] World Health Organisation. Health workforce requirements for universal health coverage and the Sustainable Development Goals. Human Resources for Health Observer Series No 17. Background paper No 1 to the Global Strategy on Human Resources for Health. Geneva, Switzerland: WHO Press; 2016. Available at: https://www.who.int/hrh/resources/healthobserver17/en/ [accessed 06.09.19].

[3] OECD. Health Workforce Policies in OECD Countries: Right Jobs, Right Skills, Right Places. OECD Health Policy Studies. OECD Publishing, Paris: 2016. Available at: http://www.oecd.org/health/health-systems/health-workforce-policies-in-oecd-countries9789264239517-en.htm [accessed 06.09.19].

[4] Hooker RS, Cawley JF, Everett CM. Introduction and Overview of the Profession. In: Hooker RS, Cawley JF, Everett CM, editors. Physician Assistants Policy and Practice. (4 ${ }^{\text {th }}$ ed.). Philadelphia, PA: F.A. Davis Company; 2017. p.1-14.

[5] Faculty of Physician Associates at the Royal College of Physicians. Who are physician associates?; 2019. Available at: https://www.fparcp.co.uk/about-fpa/Who-are-physicianassociates [accessed 06.09.19]. 
[6] Mahase E. GMC will regulate physician associates, government announces. BMJ 2019; 366. doi.org/10.1136/bmj.14783

[7] Maier CB, Batenburg R, Birch S, Zander B, Elliott R, Busse R. Health workforce planning: which countries include Nurse Practitioners and Physician Assistants and to what effect? Health Policy 2018; 122: 1085-92. doi.org/10.1016/j.healthpol.2018.07.016

[8] Faculty of Physician Associates at the Royal College of Physicians. Frequently Asked Questions; 2019. Available at: https://www.fparcp.co.uk/about-fpa/faqs [accessed 06.09.19].

[9] BBC News. NHS plans rapid expansion of 'doctor's assistant jobs; 2014. Available at: www.bbc.co.uk/news/health-28902132 [accessed 06.09.19].

[10] NHS. Interim NHS People Plan; 2019. Available at: https://www.longtermplan.nhs.uk/wp-content/uploads/2019/05/Interim-NHS-PeoplePlan_June2019.pdf [accessed 06.09.19].

[11] Akabogu U, Jenkins N, Stanfield R and Baker-Lacey D. The National Physician Associate Expansion Programme. Future Healthcare Journal 2017; 4: s9. doi:10.7861/futurehosp.4-2-s9 [12] OECD. Changing patterns in the international migration of doctors and nurses to OECD countries. In: OECD. International Migration Outlook 2015. Paris: OECD Publishing; 2015. p.105-82. Available at: https://doi.org/10.1787/migr_outlook-2015-en [accessed 06.09.19].

[13] OECD. Health workforce migration. OECD; 2019. Available at: https://stats.oecd.org/Index.aspx?DataSetCode=HEALTH_WFMI [accessed 06.09.19].

[14] Buchan J, Campbell J, Dillon I, Charlesworth A. Labour market change and the international mobility of health workers. Health Foundation working paper: number 5. Health Foundation; 2019. Available at: https://www.health.org.uk/publications/labour-marketchange-and-the-international-mobility-of-health-workers [accessed 06.09.19].

[15] Barriball L, Bremner J, Buchan, J, Craveiro I, Dielman M, et al. Recruitment and Retention of the Health Workforce in Europe. Final report. Brussels: European Commission; 2015. Available at: 
https://ec.europa.eu/health/sites/health/files/workforce/docs/2015_healthworkforce_recruitme nt_retention_frep_en.pdf [accessed 06.09.19].

[16] Drennan VM and Ross F. Global nurse shortages - the facts, the impact and action for change. Br Med Bull 2019; 130: 25-37. doi.org/10.1093/bmb/ldz014

[17] Humphries N, Connell J, Negin J and Buchan J. Tracking the leavers: towards a better understanding of doctor migration from Ireland to Australia 2008-2018. Hum Resour Health 2019; 17: 36. doi.org/10.1186/s12960-019-0365-5

[18] Freeman TR, Petterson S, Finnegan S and Bazemore A. Shifting tides in the emigration patterns of Canadian physicians to the United States: a cross-sectional secondary data analysis. BMC Health Serv Res 2016; 16; 678. doi:10.1186/s12913-016-1908-2

[19] Gould R and Horsburgh S. What motivates doctors to leave the UK NHS for a "life in the sun" in New Zealand; and, once there, why don't they stay? Hum Resour Health 2015; 13: 75. doi.org/10.1186/s12960-015-0069-4

[20] Legido-Quigley H, Saliba V, McKee M. Exploring the experiences of EU qualified doctors working in the United Kingdom: a qualitative study. Health Policy 2015; 119: 494502. doi:10.1016/j.healthpol.2014.08.003

[21] Quantin C, Abbas R, Hagi M, Le Breton G, Romestaing M, Carnet D. Comparison of British and French expatriate doctors' characteristics and motivations. BMJ Open 2012; 2: e001706. doi:10.1136/bmjopen-2012-001706

[22] Sharma A, Lambert T, Goldacre M. Why UK-trained doctors leave the UK: cross sectional survey of doctors in New Zealand. JRSM 2012; 105: 25-34. doi:10.1258/jrsm.2011.110146

[23] Blitz B. Brain circulation: the Spanish medical profession and international medical recruitment in the UK. J Eur Soc Policy 2005; 15: 363-9. doi:10.1136/bmj.330.7485.210

[24] Snelgrove H, Kuybida Y, Fleet M and McAnulty G. "That's your patient. There's your ventilator"; exploring induction to work experiences in a group of non-UK EEA trained anaesthetists in a London hospital: a qualitative study. BMC Med Educ 2015; 15. doi:10.1186/s12909-015-0331-4 
[25] Toffler BL. Occupational Role Development: The Changing Determinants of Outcomes for the Individual. Administrative Science Quarterly 1981; 26: 396-418. doi:10.2307/2392514

[26] Graen G. Role making processes within complex organizations. In: Dunnette MD, editor. Handbook in industrial and organizational psychology. Chicago: Rand Mcnally; 1976. p.120145.

[27] Crotty M. The foundations of social research: meaning and perspective in the research process, Thousand Oaks, CA: Sage; 1998.

[28] Holloway I and Wheeler S. Qualitative Research in Nursing and Health Care. ( $3^{\text {rd }}$ ed.). Chichester: Wiley; 2010.

[29] Pope C, Ziebland S and Mays N. Qualitative research in health care. Analysing qualitative data. BMJ 2000; 320: 114-6. doi:10.1136/bmj.320.7227.114

[30] Christians CG. Ethics and politics in qualitative research. In: Denzin NK, Lincoln YS, editors. Handbook of Qualitative Research. London: Sage; 2000. p.133-55.

[31] Maxwell E, Baillie L, Rickard W and McLaren SM. Exploring the relationship between social identity and workplace jurisdiction for new nursing roles: A case study approach. Int $\mathbf{J}$ Nurs Stud 2013; 50: 622-31. doi:10.1016/j.ijnurstu.2012.10.015

[32] Friedrich LA, Prasun MA, Henderson L and Taft L. Being a seasoned nurse in active practice. J Nurs Manag 2011; 19: 897-905. doi:10.1111/j.1365-2834.2011.01294

[33] Kent LN. For love or money: registered nurses who return to hospital practice. J Nurs Manag 2015; 23: 599-603. doi:10.1111/jonm.12185

[34] Sidebotham M, Ahern K. Finding a way: The experiences of UK educated midwives finding their place in the midwifery workforce of Australia. Midwifery 2011; 27: 316-23. doi:10.1016/j.midw.2011.01.002

[35] Young R, Noble J, Mahan A, Maxted M, Grant J, Sibbald B. Evaluation of international recruitment of health professionals in England. J Health Serv Res Pol 2010; 15: 195-203. doi.org/10.1258/jhsrp.2010.009068 
[36] Sturges JE, Hanrahan KJ. Comparing Telephone and Face-to-Face Qualitative Interviewing: A Research Note. Qual Res 2004; 4: 107-18. doi.org/10.1177/1468794104041110 